\title{
Effect of Prior-Heat Treatments on the Creep Behavior of an Industrial Drawn Copper
}

\author{
Zakaria Boumerzoug ${ }^{*}$, Salim Gareh, Abdellatif Beribeche
}

Laboratory of Metallicans Semiconductor Materials, University of Biskra, Biskra, Algeria.

Email: *zboumerzoug@yahoo.fr

Received September $3^{\text {rd }}, 2012$; revised October $5^{\text {th }}, 2012$; accepted October $16^{\text {th }}, 2012$

\begin{abstract}
The effect of prior-heat treatments at $500^{\circ} \mathrm{C}, 600^{\circ} \mathrm{C}$ and $700^{\circ} \mathrm{C}$ on the creep behavior of an industrial drawn copper has been studied under constant stresses $(98,108$ and $118 \mathrm{MPa})$ and temperatures $\left(290^{\circ} \mathrm{C}\right.$ and $\left.340^{\circ} \mathrm{C}\right)$. The results revealed that the creep behavior and the creep life of the material depend strongly on these prior-heat treatments. The apparent activation energy $Q_{c}$ for different creep tests of a drawn copper wire was calculated. The fracture mechanism of the material is characterized using optical microscopy.
\end{abstract}

Keywords: Copper; Creep; Drawn Wire; Heat Treatment

\section{Introduction}

In material science, creep is the tendency of a solid material to slowly move or deform permanently under the influence of stresses. In general, creep occurs in three stages: Primary, secondary and tertiary stage. For primary stage which occurs at the beginning of the tests, the creep is mostly transient. In secondary stage, the rate of creep becomes roughly steady and is called steady state creep. In tertiary stage, the creep rate increases at a high rate leading to the fracture of the material.

The mechanism governing creep in pure metals remains the subject of unresolved debate [1]. The creep behavior of industrial metals is even more complicated. The mechanism responsible for the creep is driven by several parameters such as variation of grain shape [2], grain size distribution [3], grain growth [4] and complex twin/CSL boundary structure [5]. Additional complications such as inert precipitate and particle accumulation at grain boundaries in alloys [6] make theoretical interpretation of the creep data more difficult.

Copper in particular has attracted attention due to its good properties such as low resistivity. Due to its high ductility which is the ability to be easily drawn into wires, copper dawning is very attractive manufacturing process. The wire drawing is a process that is used for the manufacturing of metal wires. Copper wire has long been the preferred conductor material. The demands of electrical technology require copper to have higher mechanical properties and to be capable of using at elevated operat-

"Corresponding author. ing temperatures while still retaining the good conductivity for which it is selected in the first place [7].

On the other hand, its ductility can influence its creep characteristics making the study of resistance to creep one of the prime engineering importances. Consequently, it is important to characterize its creep and creep behaviors because this material requires adequate creep resistance to ensure reliable performance in service. We note that there were creep tests carried out on high purity copper wires [8-16]. However, some limited scientific works have been concerned on creep behavior of drawn copper [15,16]. Schwope, Smith and Jackson [15], have been studied creep properties of several types of commercial coppers. In their investigation, data were presented showing the effect of cold work on the short time creep strengths of various types of commercial copper under several conditions. Ayensu, Quainoo, and Adjepong [16], have been investigated creep mechanism of an industrial hard-drawn copper wires which were tested at temperatures of $300^{\circ} \mathrm{C}, 400^{\circ} \mathrm{C}$ and $500^{\circ} \mathrm{C}$ under uniaxial stresses of 7.08, 14.16 and $21.24 \mathrm{MPa}$. From activation energy values the creep mechanism is governed by grain boundary sliding.

This investigation is an attempt to understand the effect of prior heat treatment at $500^{\circ} \mathrm{C}, 600^{\circ} \mathrm{C}$ and $700^{\circ} \mathrm{C}$ on creep behavior of an industrial drawn copper.

\section{Experimental Techniques}

The material used in this study is an industrial copper electric wire of composition $99.9 \mathrm{Cu}, 0.001 \mathrm{Bi}, 0.002 \mathrm{Sb}$, $0.002 \mathrm{As}, 0.005 \mathrm{Fe}, 0.002 \mathrm{Fe}, 0.002 \mathrm{Ni}, 005 \mathrm{~Pb}, 0.002 \mathrm{Sn}$, 
$0.004 \mathrm{~S}, 0.004 \mathrm{Zn}$ and 0.073 others elements. Creep experiments were conducted in a creep test machine using samples having gauge length of $10 \mathrm{~mm}$ and cross sectional area of $8 \times 3.2 \mathrm{~mm}$. The creep specimens were tested at temperatures $290^{\circ} \mathrm{C}$ and $340^{\circ} \mathrm{C}$ and a stress of 98, 108 and $118 \mathrm{MPa}$. All of the tests were continued until fracture occurred. The strain-time readings were continuously recorded by PC-based data acquisition system (Figure 1). Optical microscopy was used as complementtary technique to illustrate the microstructural evolution of the drawn copper during prior-heat treatments $\left(500^{\circ} \mathrm{C}, 600^{\circ} \mathrm{C}\right.$ and $\left.700^{\circ} \mathrm{C}\right)$ and after fracture.

\section{Results and Discussion}

Strain versus time plots after creep tests at $340^{\circ} \mathrm{C}$ and 98 MPa of heat treated drawn copper are presented in Figure 2. The non-heat treated material is used as a reference sample. It is clear that this last material has the shortest life time, (time of rupture $=12 \mathrm{~min}$ ). In addition, the creep test curve of this material exhibits the three stages of creep. However, from these curves, the heat

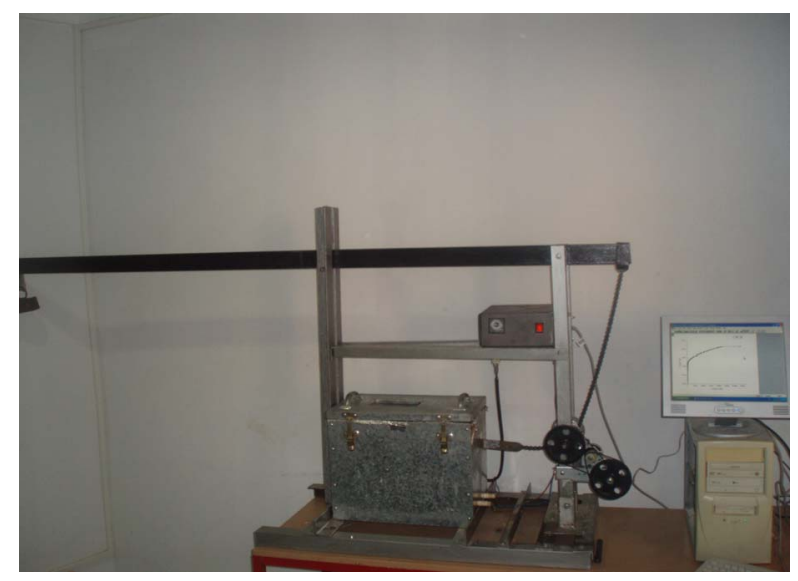

Figure 1. Creep machine test.

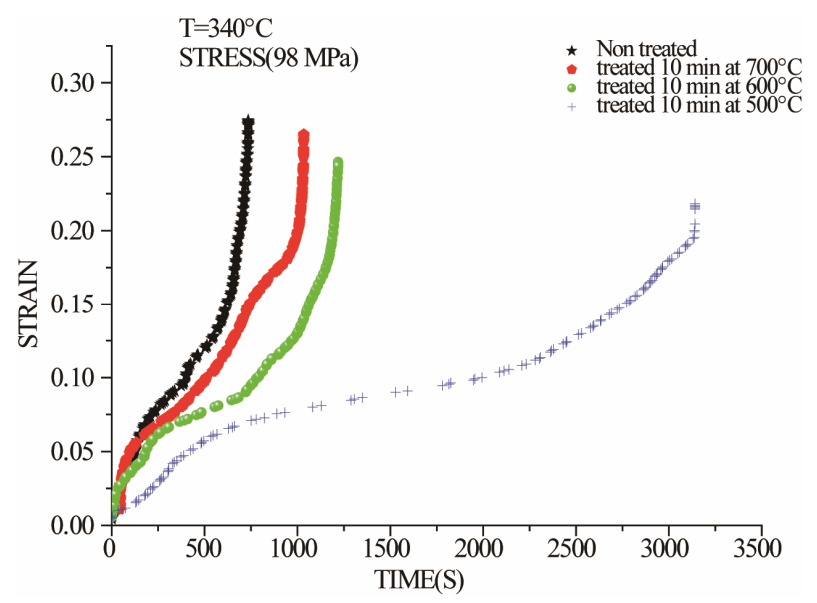

Figure 2. Creep curves of drawn copper at $340^{\circ} \mathrm{C}$ and 98 MPa. treated materials have the longer creep life. Moreover, time to fracture depends on temperature of the prior-heat treatment. The drawn copper which has been heated 10 min at $500^{\circ} \mathrm{C}$ exhibits the longer creep life. In contrary to our results, Schwope, Smith, and Jackson [15] have investigated several commercial copper and reported that cold work increases its creep strength.

By increasing the temperature of prior-heat treatment of drawn copper to $700^{\circ} \mathrm{C}$, the creep behavior changes because the life time of the material becomes shorter in comparison to the other heat treated materials. This result can be explained by optical microscopy of drawn copper before (Figure 3(a)) and after heat treatments at $500^{\circ} \mathrm{C}$ (Figure 3(b)) and $700^{\circ} \mathrm{C}$ (Figure 3(c)). In this case, heat treatment at $700^{\circ} \mathrm{C}$ increases the grain size in comparison to the rest of the heat treated materials. However, the heat treatment of drawn wire at $500^{\circ} \mathrm{C}$ during $10 \mathrm{~min}$ induces primary recrystallization which is characterized by finer grains. This last microstructure gives the material a longer time to fracture. It is known that the increased strengthening with smaller grain size is associated with the increased dislocation density in the grain interiors due to the activation dislocation sources [17].

By increasing the applied stress during a creep test, the same phenomenon is observed. The results of creep tests obtained at 108 and $118 \mathrm{MPa}$ are shown respectively in Figures 4 and 5. In this case, primary creep was observed immediately after loading in all four samples. The duration of the primary stage increases with increasing the temperature of prior heat treatment.

The curves of strain versus stress (Figure 6) show that the strain rate varies linearly with the applied stress. Consequently, the apparent activation energy can be deduced. The activation energy for creep $Q_{c}$ is defined as [18]:

$$
Q_{c}=\left[\frac{\partial \log \dot{\varepsilon}}{\partial(-1 / K T)}\right]_{\sigma}
$$

Thus, the activation energy $Q_{c}$ can be derived from the slope of $\log \left(\frac{\partial \varepsilon}{\partial t}\right)$ versus $\frac{1}{T}$ plots. The values of the apparent activation energy $Q_{c}$ for different creep tests are shown in Table 1. These values of $Q_{c}$ vary from 80.75 to $147.11 \mathrm{~kJ} / \mathrm{mol}$. The non-heat treated drawn copper has the higher activation energy. The heat treated material at $700^{\circ} \mathrm{C}$ has the highest value of $Q_{c}$ compared with the other heat treated materials. The change in apparent activation energy implies a change in the creep mechanism. Other investigations have found that the values of the apparent energy $Q_{c}$ are equal to $106.1 \pm 0.2$ and $90.3 \pm$ $2.1 \mathrm{~kJ} / \mathrm{mol}$ for the impressed and the pressed sample respectively [19].

For pure copper an average of the activation energies of $112.4 \mathrm{~kJ} / \mathrm{mol}^{-1}$ has been reported by Akbari, Mahmadi, 


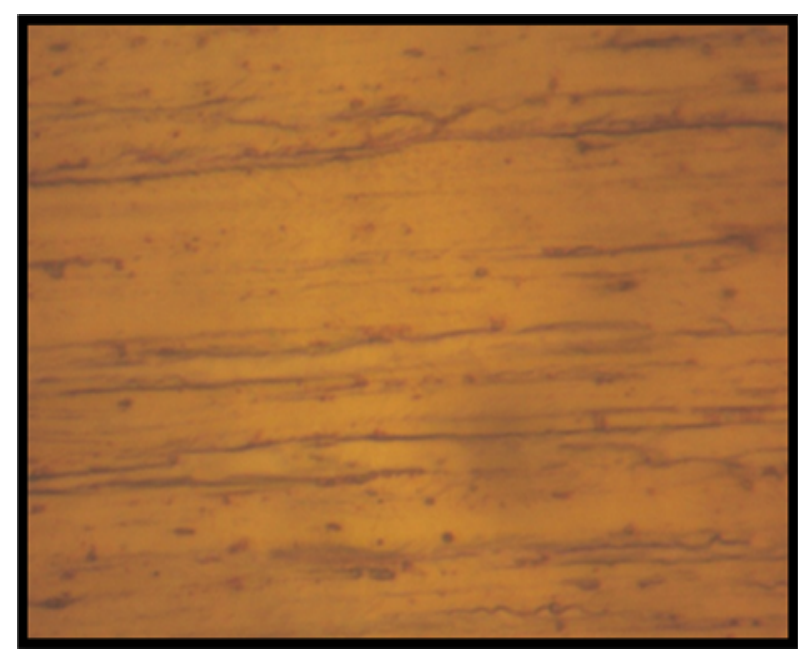

(a)

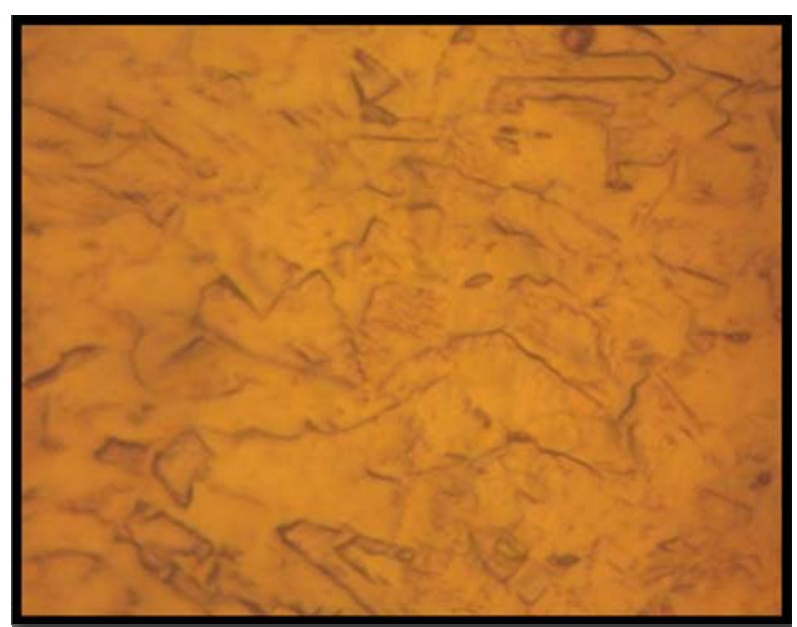

(b)

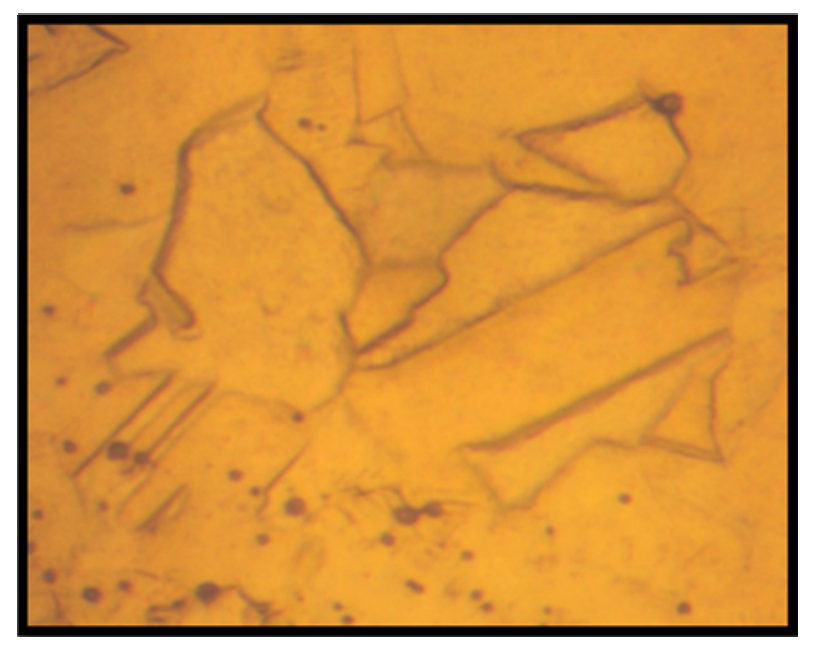

(c)

Figure 3. Microstructures of drawn copper: (a) Before heat treatement, (b) after heat treatement for $10 \mathrm{~min}$ at (b) $500^{\circ} \mathrm{C}$ and (c) $700^{\circ} \mathrm{C}$.

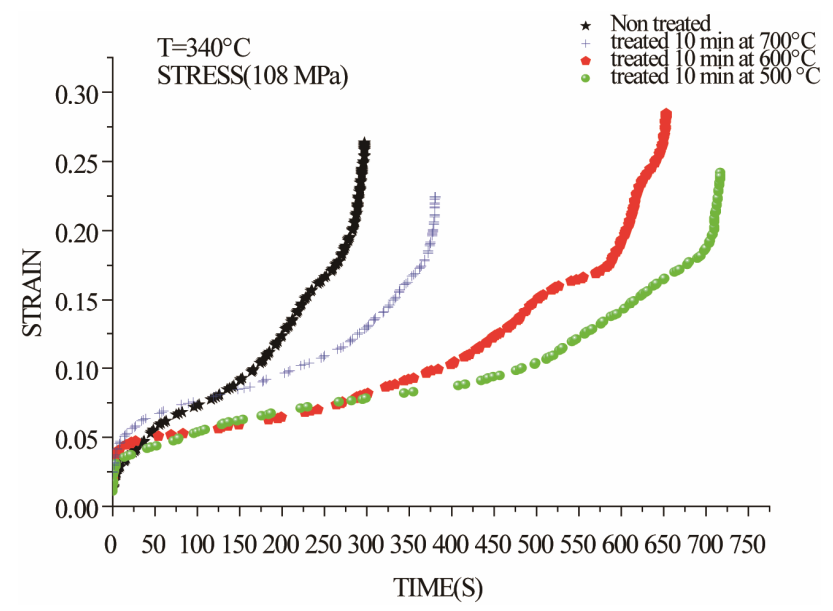

Figure 4. Creep curves of drawn copper at $340^{\circ} \mathrm{C}$ and 108 Mpa.

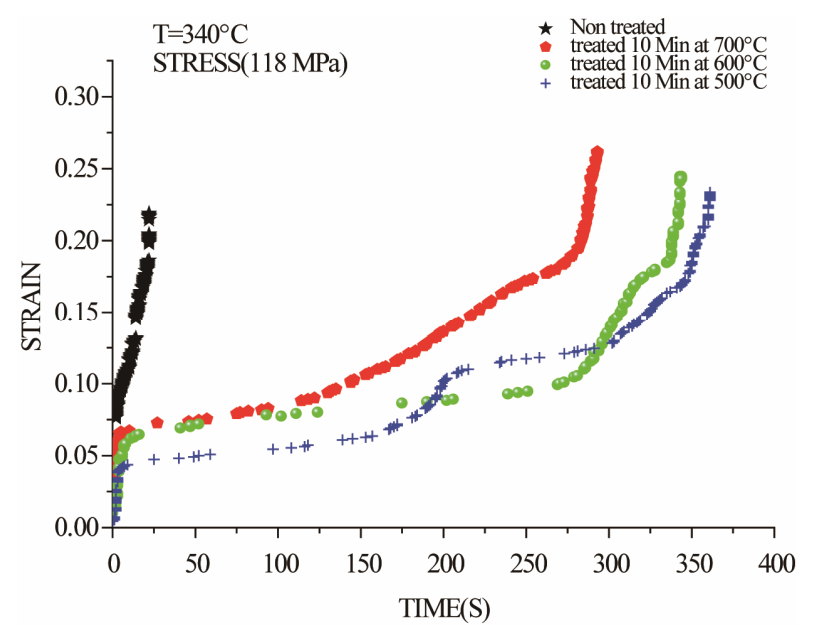

Figure 5. Creep curves of drawn copper at $340^{\circ} \mathrm{C}$ and 118 Mpa.

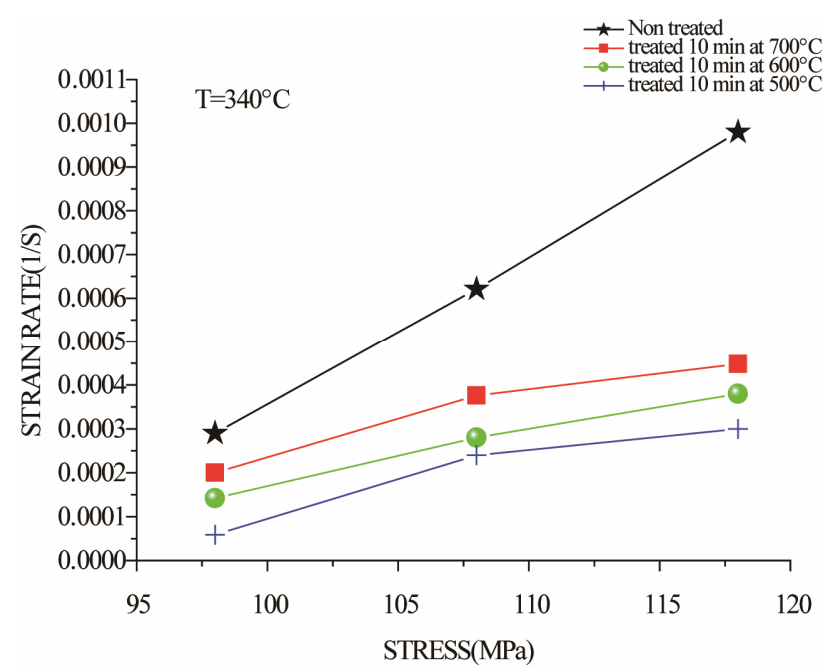

Figure 6. Strain rate plotted against applied stress for copper wires tested at $340^{\circ} \mathrm{C}$ (drawn wire non-treated, treated $10 \mathrm{~min}$ at $500^{\circ} \mathrm{C}, 600^{\circ} \mathrm{C}$ and $700^{\circ} \mathrm{C}$ ). 
Table 1. Values of the apparent activation energy $Q_{c}$ for different creep tests of a drawn copper wire.

\begin{tabular}{cccc}
\hline$Q_{c}(\mathrm{~kJ} / \mathrm{mol})$ & Non treated & Treated 10 min at $700^{\circ} \mathrm{C}$ & Treated 10 min at $600^{\circ} \mathrm{C}$ \\
\hline$\sigma=118 \mathrm{MPa}$ & 147.11 & 127 & 105.47 \\
$\sigma=108 \mathrm{MPa}$ & 121 & 106.16 & 103 \\
$\sigma=98 \mathrm{MPa}$ & 110.2 & 94 & 86.55 \\
\hline
\end{tabular}

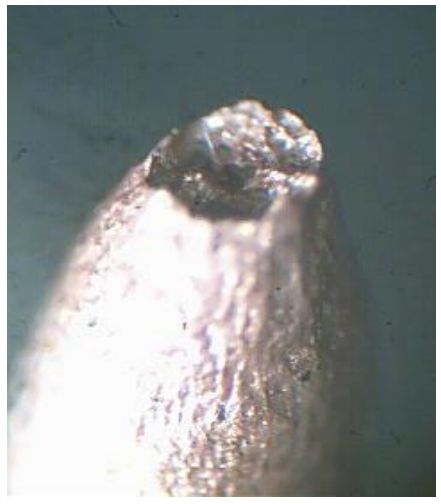

(a)

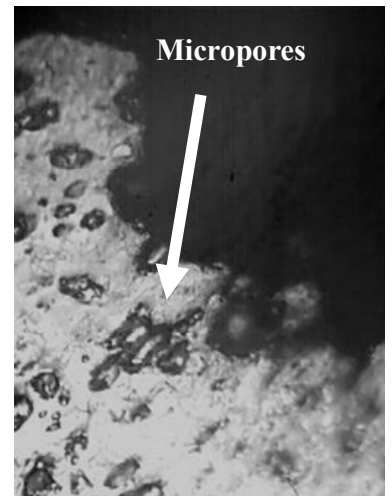

(b)

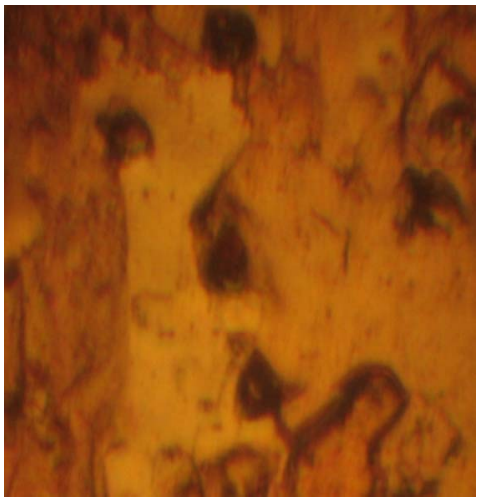

(c)

Figure 7. Profil view after creep test $\left(118 \mathrm{MPa}, 340^{\circ} \mathrm{C}\right)$ of drawn copper. (a) Necking zone after creep test; (b) High density of micropores near fracture zone; (c) Low density of micropores far in the fracture zone.

Karsaz and Geranmayeh [20]. They have indicated that these values of activation energies are close to $138 \mathrm{~kJ} /$ $\mathrm{mol}^{-1}$ for dislocation climb in copper. In this present study, the values of apparent activation energy are close to this mechanism of climbing.

In order to observe the microstrucrural features that have been generated during the creep test, the wires were examined by optical microscopy. Profil views of drawn copper after creep test are presented in Figure 7. We suggest that the main cause of the fracture of the copper during creep test is the presence of high density of micro-porisity in this industrial material as it is shown in Figure 7(b). Cracks can occur in creeping metals from pre-exciting flaws, fatigue, corrosion-related processes, and porosity. In our case, crack growth is caused by the coalescence of micro-pores with each other which induces the fracture of the material at the necking zone. For example, Williams and Thomas [21] studied the creep of high-purity copper, where micro-cracking phenomenon has been observed in these materials during creep tests which leaded to complete fracture. It has been found by Zinkle and Lee [22] that the origin of the formation of voids in copper was the effect of oxygen.

\section{Conclusions}

The effect of prior-heat treatments on the creep behavior of an industrial drawn copper has been studied under constant stresses and temperatures. The main results can be summarized as:
The difference of the creep behavior is attributed to the initial microstructure of drawn copper, i.e., the finer grains obtained after isothermal annealing at $500^{\circ} \mathrm{C}$ gives the material a longer time to fracture during creep test. However, the non-heat treated drawn copper has the higher activation energy and its creep mechanism is governed by climbing process. The origin of the fracture during creep test was the formation of micro-pores at the necking zone.

\section{REFERENCES}

[1] B. Wilshire, "Observations, Theories and Predictions of High Temperature Creep Behaviour," Metallurgical and Materials Transactions A, Vol. 33, No. 2, 2002, pp. 241248. doi:10.1007/s11661-002-0086-5

[2] J. H. Schneibel, R. L. Coble and R. M. Cannon, "The Role of Grain Size Distributions in Diffusional Creep," Acta Metallurgica, Vol. 29, No. 7, 1981, pp. 1285-1290. doi:10.1016/0001-6160(81)90019-5

[3] P. M. Hazzledine and J. H. Scheibel, "Theory of Coble Creep for Irregular Grain Structures," Acta Metallurgica et Materialia, Vol. 41, No. 4, 1993, pp. 1253-1262. doi:10.1016/0956-7151(93)90176-S

[4] B. Burton, "A Theoretical Upper Limit to Coble Creep Strain Resulting from Concurrent Grain Growth," Journal of Materials Science, Vol. 28, No. 18, 1993, pp. 49004903. doi:10.1007/BF00361153

[5] P. A. Thorsen and J. B. Sorensen, "Deposition of Material at Grain Boundaries in Tension Interpreted in Terms of Diffusional Creep," Materials Science and Engineering: 
$A$, Vol. 265, No. 1-2, 1999, pp. 140-145. doi:10.1016/S0921-5093(98)01139-3

[6] B. Burton and W. B. Beere, "Grain Boundary Diffusional Creep of Materials Containing Particles," Philosophical Magazine A, Vol. 43, No. 6, 1981, pp. 1561-1568. doi:10.1080/01418618108239527

[7] V. Callcut, "High Copper Alloys-High Strength Coppers for Demanding Electrical Applications," 2006. http://www.copper.org/publications/newsletters/innovatio ns/2006/09/high_cu_alloys.html

[8] P. Regnier and M. F. Felsen, "Influence of Burning Grain Boundaries on the Creep Rate of Diffusion to Son Bamboo Structure and Determination of the Corresponding Surface Tensio," Philosophical Magazine A, Vol. 43, No. 1, 1981, pp. 11-27. doi: $10.1080 / 01418618108239390$

[9] M. C. Inman, D. McLean and H. R. Tipler, "Interfacial Free Energy of Copper Antimony Alloys," Proceedings of the Royal Society of London, Vol. 273, 1963, p. 538.

[10] J. H. Hoage, "Surface Tension Studies on Uranium and Copper," US Atomic Commission Report HW-78132, 1963.

[11] H. Udin, A. J. Shaler and J. Wulff, "The Surface Tension of Solid Copper," Transactions of the Metallurgical Society of AIME, Vol. 185, 1949, p. 186.

[12] H. Udin, Transactions of the Metallurgical Society of AIME, Vol. 189, 1951, p. 63.

[13] A. L. Pranatis and G. M. Pound, "Viscous Flow of Copper at High Temperatures," Transactions of the Metallurgical Society of AIME, Vol. 203, 1955, p. 644.

[14] V. Srivastava, K. R. McNee, H. Jones and G. W. Greenwood, "The Effect of Low Stresses on Creep and Surfaces
Profiles of Thin Copper Wires," Acta Materialia, Vol. 51, No. 15, 2003, pp. 4611-4619. doi:10.1016/S1359-6454(03)00298-2

[15] A. D. Schwope, K. F. Smith and L. R. Jackson, "The Comparative Creep Properties of Several Types of Commercial Coppers," Transactions of the Metallurgical Society of AIME, Vol. 185, 1950, p. 409.

[16] A. Ayensu, G. K. Quainoo and S. K. Adjepong, "Grain Boundary Creep in Copper," Journal of Materials Science Letters, Vol. 12, No. 13, 1993, pp. 1008-1010. doi:10.1007/BF00420200

[17] H. Conrad, "Effect of Grain Size on the Lower Yield and Flow Stress of Iron and Steel," Acta Metallurgica, Vol. 11, 1963, pp. 75-77.

[18] M. E. Kasner, M. Teresa and P. Prado, "Fundamentals of Creep in Metals and Alloys," Elsevier, Tokyo, 2004.

[19] J. Dvorak, V. Sklenicka, P. Kral, M. Svoboda and I. Saxl, "Characterization of Creep Behaviour and Microstructure Ganges in Pure Copper Processed by Equal-Channel Angular Dressing," Reviews on Advanced Materials Science, Vol. 25, 2010, pp. 225-232.

[20] A. Akbari-Fakhrabadi, R. Mahmadi, A. Karsaz and A. R. Geranmayeh, "Creep Behavior of Copper and $\mathrm{Cu}-0.3 \mathrm{Cr}-0.1$ Ag Alloy," Journal of Engineering Materials and Technology, Vol. 132, No. 4, 2010, Article ID: 044501. doi:10.1115/1.4002356

[21] W. D. Jenkins and G. Digges, "Creep of High-Purity Copper," Journal of Research of the National Institute of Standards and Technology, Vol. 45, No. 2, 1950.

[22] S. J. Zinkle and E. H. Lee, "Effect of Oxygen on Vacancy Cluster Morphology in Metals," Metallurgical and Materials Transactions, Vol. 21, No. 5, 1990, pp. 1037-1051. 